\title{
海面水温特性に着目した台風シミュレーションの再構築 \\ Discussion of Improved Typhoon Simulation Model Focusing on Sea Surface Temperature Properties
}

\author{
小林俊之* \\ Toshiyuki KOBAYASHI
}

\begin{abstract}
SUMMARY
Typhoon simulation considering sea-surface temperature can estimate recurrence wind speed of typhoon when sea surface temperature changes due to global warming. Existing tracking model of the simulation showed different typhoon properties from observed values. It has some problems such as the criterion for determining the end of the typhoon was not clear, so improvements were made for each problem. From the view point of the extreme value distribution of annual maximum wind speed, it was shown that the relation between friction-free wind and surface wind speed including the difference of average time is a constant depending on the location and altitude. According to the results of the improved simulation, 100-year recurrence wind speed may increase by $5 \mathrm{~m} / \mathrm{s}$ at almost all regions in Japan by the end of the 21 st century.
\end{abstract}

key words: Typhoon simulation, The relation between friction-free wind and surface wind speed, Recurrence wind speed, Global warming, Sea-surface temperature

1.はじめに

地球温暖化により，海面水温が上昇して台風の強度に 影響を与えることが懸念されている. 道路橋の設計基準 風速として用いられる風速の 100 年再現期待值は, 台風 による強風が支配的であることが多い. 海面水温上昇と 風速における 100 年再現期待值の増加率の関係を定量的 に知ることは, 構造物の長寿命化において重要である. 風速の再現期待值を求める一つの手法として, 統計的 台風シミュレーションがある、これは一般的に移動モデ ルと強風場モデルで構成される．移動モデルは過去の台 風の中心座標と中心気圧を統計的にモデル化したもので,
長期間分(例えば 1 万年分)の疑似的な台風を生成できる. 強風場モデルは台風域の強風環境を経験的式と力学的近 似式を用いてモデル化したものである.

勝地ら 1)は台風の発生から終了まで海面水温(SST)を考 慮して計算できる移動モデルを有した統計的台風シミュ レーションにより, 将来の風速について議論をしている. しかし, 移動モデルの再現性が未評価である. 一方, 強 風場モデルに含まれる $\mathrm{FFW}($ 地表の摩擦の影響を受けな い上空風から地上風を推定するためのモデルとして, 高 さ方向に風速比が計算可能なものが孟ら 2)などにより提 案されている. しかし, 正確なパラメータを求めるには

\footnotetext{
*横浜国立大学大学院都市イノベーション学府都市地域社会専攻

Department of Infrastructure and Urban Society, Institute of Urban Innovation, Yokohama National University (指導教員 山田均教授)
} 

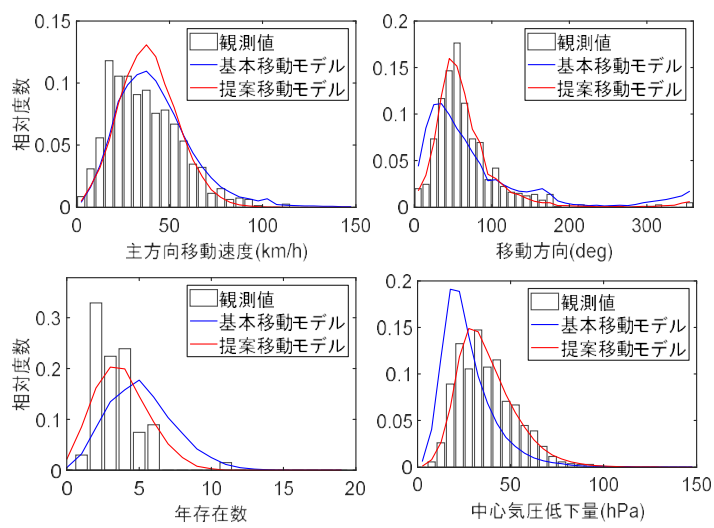

図 1 相対度数分布による比較

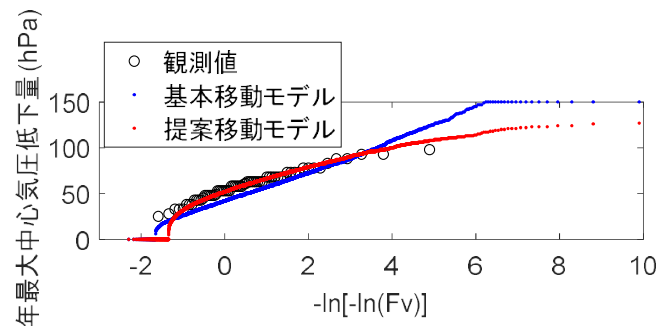

図 2 年最大中心気圧低下量の極值分布による比較

台風時の観測值が複数必要であり，任意地点で使用する ことが困難である.

本研究では，勝地らの移動モデル（以下，基本移動モデ ル)の再現性評価を行い，改良を行った．また，極值分布 に着目して FFW と地上風の風速比を検討した. 最後に, SST 偏差と風速の 100 年再現期待值の関係を調べた.

\section{2. 移動モデルの再現性向上}

2. 1 基本移動モデルと再現性評価

基本移動モデルのシミュレーション範囲は北緯 4 50，東経 99 180 である. パラメータを格納する 格子の大きさは南北方向に $2^{\circ}$, 東西方向に $3^{\circ}$ である. 計算のフローはシンプルで，台風の年発生数を確率分布 から決定する. 発生地点, 発生時の移動速度 $\vec{C}$, 中心気 圧低下量 $\Delta p$ (中心気圧から $1013 \mathrm{hPa}$ 引いた量)も確率分 布から決定し， $\vec{C}, \Delta p$ を 6 時間毎に逐次計算する. そ して, シミュレーション範囲外に出る，もしくは $\Delta p$ が $5 \mathrm{hPa}$ 以下になったときに台風は終了する. この流れを試 行年数分繰り返すことで, 長期間分の台風を生成できる. 基本移動モデルから 1 万年分の台風を生成し，大阪から $500 \mathrm{~km}$ 圈内に存在した台風の主方向移動速度, 移動方向 (東を $0^{\circ}$ として, 反時計回りに正), 年存在数, $\Delta p$ の相 対度数分布を観測值と比較した結果を図 1 に示す. 年最
表 1 移動モデルの主な改良点

\begin{tabular}{|c|c|c|}
\hline & 基本移動モデル & 提案移動モデル \\
\hline $\begin{array}{l}\text { 発生地点 } \\
\text { (mod_oc) }\end{array}$ & $\begin{array}{l}\text { 経験的累積度数 } \\
\text { 分布 }\end{array}$ & 2 変量正規分布 \\
\hline $\begin{array}{l}\text { 発生時 } \vec{C} \\
\text { (mod_oc_C) }\end{array}$ & $\begin{array}{l}\text { 各成分に対し } 1 \\
\text { 変量正規分布 }\end{array}$ & $\begin{array}{l}\text { 両成分による } 2 \\
\text { 変量正規分布 }\end{array}$ \\
\hline $\begin{array}{l}\vec{C} \text { の逐次計算 } \\
(\bmod \operatorname{seg} \mathrm{C})\end{array}$ & $\begin{array}{l}\text { 各成分が独立し } \\
\text { た回帰式 }\end{array}$ & $\begin{array}{l}\text { 両成分を考慮し } \\
\text { た回帰式 }\end{array}$ \\
\hline $\begin{array}{l}\text { 終了条件 } \\
\text { (mod_end_dp) }\end{array}$ & $\begin{array}{l}\Delta p \text { が } 5 \mathrm{hPa} \text { 以 } \\
\text { 下, シミュレーシ } \\
\text { ヨン範囲外に出 } \\
\text { る }\end{array}$ & $\begin{array}{l}\text { 左記に加え, 北緯 } \\
31.5^{\circ} \text { 以北に存 } \\
\text { 在する台風は終 } \\
\text { 了時中心気圧低 } \\
\text { 下量の確率分布 } \\
\text { に従わせて終了 }\end{array}$ \\
\hline $\begin{array}{l}\text { 逐次計算の閾值 } \\
\text { を超えたときの } \\
\text { 扱い } \\
\text { (mod_threshold) }\end{array}$ & $\begin{array}{l}\text { 閾値を頭打ちと } \\
\text { していた }\end{array}$ & $\begin{array}{l}\text { 閾值を超えたら } \\
\text { 再計算をさせた }\end{array}$ \\
\hline $\begin{array}{l}\text { パラメータ推定 } \\
\text { に用いる観測值 } \\
\text { の期間 } \\
\text { (mod_period) }\end{array}$ & 1 12月 & $6 \sim 10$ 月 \\
\hline $\begin{array}{l}\text { SST 分布 } \\
\text { (mod_SSTdist) }\end{array}$ & $\begin{array}{l}\text { 6 10 月の平均 } \\
\mathrm{SST} \text { 分布を使用 }\end{array}$ & $\begin{array}{l}\text { 6 10 月の各月の } \\
\text { 平均 SST 分布を } \\
\text { 使用 }\end{array}$ \\
\hline
\end{tabular}

大中心気圧低下量の極值分布も図 2 に示寸. これより, 観測值と計算值が離れていることがわかる.

2. 2 基本移動モデルの改良と再現性評価

基本移動モデルに改良を施したモデルを提案移動モデ ルとする. 主な改良点を表 1 に示す. 改良点の詳細は文 献 3)で示されている. 提案移動モデルの再現性は困 1,2 に示すように, 向上している.

2. 3 各改良点の感度分析

提案移動モデルと, 各改良点のみを基本移動モデルに 戻した場合における計算值の図 1 と同様の相対度数分布 の適合度合いを定量的に評価するために次に示す相対誤 差指標 $K_{d}$ を用いた。

$$
K_{d}=\sum_{i=1}^{N}\left|p_{p}(i)-p_{o}(i)\right|-\sum_{i=1}^{N}\left|p_{s}(i)-p_{o}(i)\right|
$$

ここで, $p_{p}(i)$ は提案移動モデルの相対度数, $p_{s}(i)$ は各 改良点のみを基本移動モデルに戻したときの相対度数, $p_{o}(i)$ は観測值の相対度数, $i(=1,2, \ldots, N)$ は階級の番号 を意味する， $K_{d}$ が正で大きいほど，その改良により計算 值が観測值に近づくことを示す．結果を図 3 に示す．場 合によっては $K_{d}$ が負になることもあるが，台風が支配的 な関東以西の地域では再現性を向上，もしくはほとんど 変わらない結果を示した. 図 3 より, mod_threshold は 

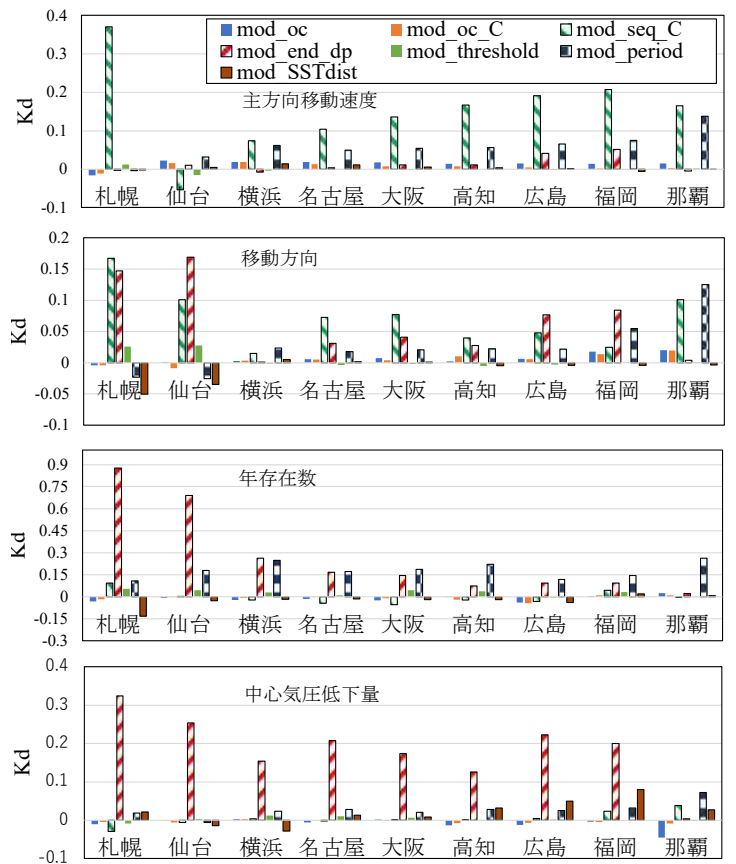

図 3 相対誤差指標による各改良点の感度分析

各台風特性の相対度数分布の再現性向上に大きな影響を 与えていないが，年最大中心気圧低下量の極值分布には 大きな影響を与えることが図 4 よりわかる.

\section{3．強風場モデルの検討}

3. 1 気圧場と FFW のモデル

気圧場には Schloemer の式, 最大風速半径の推定には 河合ら 4)の式を使用した. FFW の風速 $U_{g r}$ は次に示寸2).

$U_{g r}=-\frac{C \sin (\psi-\varphi)+f r}{2}+\sqrt{\left(-\frac{C \sin (\psi-\varphi)+f r}{2}\right)^{2}+r P_{n}}(2)$

ここで， $C, \varphi$ は台風の主方向移動速度及び移動方向, $f$ はコリオリパラメータ, $r$ は台風中心との距離, $\psi$ は は 着目点の台風中心に対する角度(東を $0^{\circ}$ として, 反時計 回りに正) $\rho$ は空気密度, $P_{n}$ は気圧傾度力である,

\section{2 極值分布に着目した FFW と地上風の比}

台風は中心との距離，風向による粗度区分などによっ て風速の鉛直分布が変化することが知られており，例え ば孟ら 2)のモデルがある.これは収束計算を必要とせず, 高速で風速值を求めることができる，まず，風向毎の粗 度長を求めた ${ }^{4}$. そして, 鹿児島地方気象台の高さ $44.9 \mathrm{~m}$ における極值分布を求め，平均化時間の補正 5) をした既 往モデルの結果を図 5 に示す。 ある程度観測值に近い分

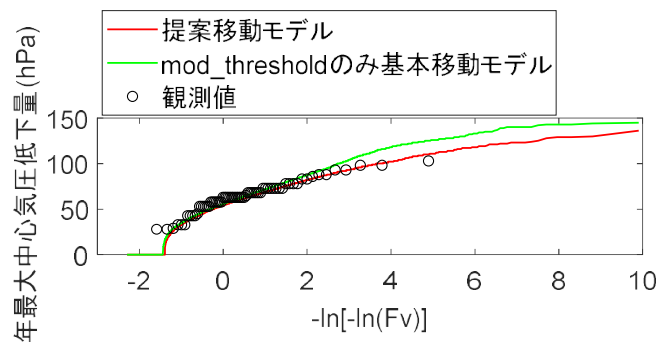

図 4 mod_threshold $の$ 年最大中心気圧低下量の極值分 布への影響

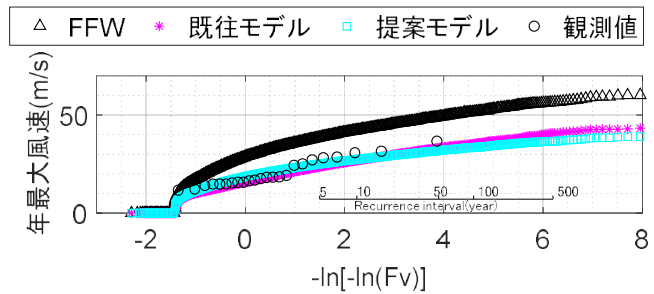

図 5 鹿児島の年最大風速における極值分布の比較

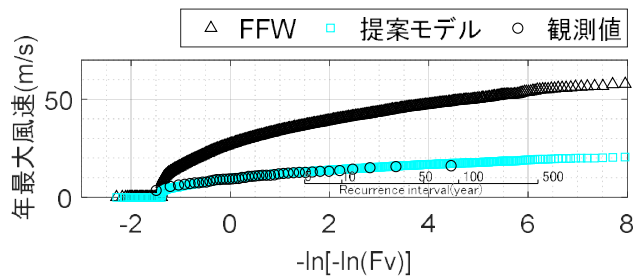

図 6 高知の年最大風速における極值分布の比較

布が得られた。しかし，粗度長を得るには台風時の観測 值が必要となるため, 任意の地点で求めるのが難しい,

本研究では, FFW の極值分布と既往モデルで求めた地 上風の極值分布が定数の比に近いことに着目した. FFW に風速比 $m$ を乗じ, 地上風の極值分布が表せるかを数值 実験した. $N$ は観測期間(年)，i は観測された年最大風速 の小さい值から数えた番号, obs $(i)$ は観測された風速値, $F F W(i)$ は obs $(i)$ の標準極值変量に対して最近傍に存在 する FFW の年最大值とする. $m=1.000$ を初期值とし, 次に示寸状態になるまで $m$ を 0.001 引く.

$$
\sum_{i=1}^{N}[m \cdot F F W(i)-o b s(i)] \leq 0
$$

これより, 最適な $m$ が求まる. 鹿児島の例を図 5 に示す. この方法で地上の極值分布を概䄈せていることがわか る.また，高知などでは非常に良く分布形状が適合して いる.（図 6)これより，FFW と地上の風速比及び平均化 時間の補正は，極值分布においては地点と高度に依存す る定数 $m$ で概社表せることがわかった. 


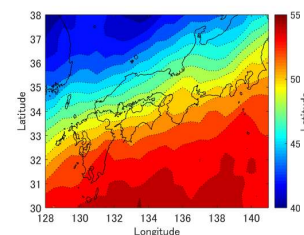

現在気候におけるFFWの100年再 現期待值 $(\mathrm{m} / \mathrm{s})$

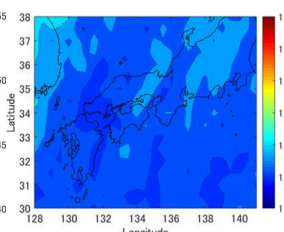

SST偏差

$1.0^{\circ} \mathrm{C}$
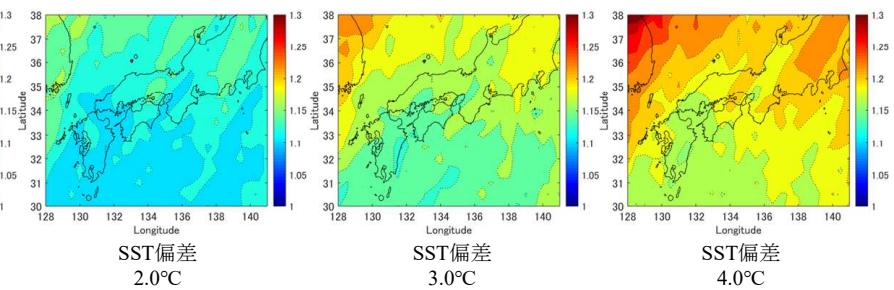

図 7 現在気候における FFW の 100 年再現期待值と各 SST 偏差における風速増加率のコンター図

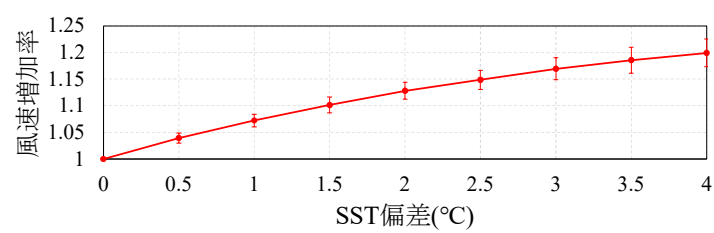

図 8SST 偏差と風速増加率の関係

(エラーバーは標準偏差)

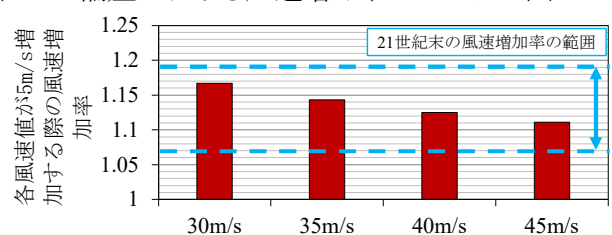

図 1021 世紀末の風速増加率の範囲と各風速值が $5 \mathrm{~m} / \mathrm{s}$ 増 加するときの風速増加率
4. SST 偏差が台風による強風に与える影響予測

4. 1 計算に使用する SST 分布

NOAA が公開する ERSSTv5 から 2006 2016 年(現在 気候)の 6 10 月における各月の平均 SST 分布を用

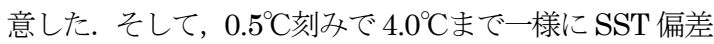
を与えたパターンを含めて, 計 9 パターン用意し, 各パ ターンの提案移動モデルから台風を生成した.

4. 221 世紀末における風速の 100 年再現期待值

$\mathrm{FFW}$ の 100 年再現期待值 $\left(F F W_{T=100}\right)$ は地上風と一定の 比で表されるため, SST 偏差を与えたときの $F F W_{T=100}$ の 現在気候に対する増加率(以下, 風速増加率)を調べた. 現 在気候における $F F W_{T=100}$ と, SST 偏差 1.0, 2.0, 3.0, $4.0^{\circ} \mathrm{C}$ 場合における風速増加率を図 7 に示寸. なお，台 風の影響が支配的である地域の多い，関東，西日本，九 州を対象とした。この結果から, SST 偏差の増加につれ て, 対象範囲全体で風速増加率が増加寸る傾向がわかっ た.SST偏差と平均風速増加率を図 8 に示寸.これより, SST 偏差に伴い平均風速増加率は単調増加するといえる。

事前調査より, MIROC-ESM ${ }^{6}$ )の RCP2.6, RCP8.5 シ ナリオによる結果では 21 世紀末には平均 $0.988 \sim 3.61^{\circ} \mathrm{C}$ の SST 偏差が生じる.したがって，21 世紀末には現在 気候で 100 年再現期待值が風速 $30,35,40,45 \mathrm{~m} / \mathrm{s}$ の 地点で $5 \mathrm{~m} / \mathrm{s}$ 以上増加する可能性が示された(図 10).

\section{5。まとめ}

本研究では, 以下のことを示した.

・基本移動モデルの計算值と観測值の各台風特性の確率 分布は比較的離れていたが，表 1 などの改良を行った 提案移動モデルでは非常に近づく結果となった.
・提案移動モデルの主な改良点は関東以西において再現 性を向上もしくはほとんど変わらない結果を示した.

・極值分布における FFW と地上の風速比及び平均化時 間の補正は，地点と高度に依存した定数 $m$ で概ね表 せることを示した.

・SST 偏差の増加と共に風速増加率は単調増加寸ること が示された。

・現在気候で風速の 100 年再現期待值が $30 \mathrm{~m} / \mathrm{s}$ 以上の地 点で, 21 世紀末には $5 \mathrm{~m} / \mathrm{s}$ 増加する可能性を示した.

参考文献

1）勝地弘ら，「海面水温の影響を導入した台風シミュレ ーション」, 日本風工学論文集, Vol. 29, No. 3, pp. $1-17,2004$

2）孟岩ら，「中立時の大気境界層における強風の鉛直 分布特性」, 日本風工学会誌, No. 6, pp. 3-14, 1996

3）小林俊之ら，「海面水温特性を考慮した台風移動モデ ルにおける中心気圧低下量再現性の向上」, 日本風工 学論文集,(投稿中)

4）河合弘泰ら，「2004 年に発生した台風の特徵と高潮 の予測・再現計算」，港湾空港技術研究所資料，第 1103 号, pp. 3-12, 2005

5）松井正宏ら，「実測と台風モデルの平均化時間の違い を考慮した台風シミュレーションによる年最大風速 の予測手法」, 日本建築学会構造系論文集, No. 506, pp. 67-74, 1998

6) Watanabe, S., et al., "MIROC-ESM:model description and basic results of CMIP5-20c3m experiments.”, Geosci. Model Dev. , Vol. 4, pp. 845-872, 2011 